08.3

\title{
Влияние кислородных вакансий на формирование и структуру филамента в мемристорах на основе диоксида кремния
}

\author{
() Е.В. Окулич, В.И. Окулич, Д.И. Тетельбаум \\ Нижегородский государственный университет им. Н.И. Лобачевского, Нижний Новгород, Россия \\ E-mail: eokulich@nifti.unn.ru
}

Поступило в Редакцию 29 июля 2019г.

В окончательной редакции 3 октября 2019г.

Принято к публикации 3 октября 2019 г.

\begin{abstract}
Установлен факт улучшения параметров мемристора на основе $\mathrm{SiO}_{2}$ при создании каскадов смещения в приповерхностном слое пленки диоксида кремния в результате облучения ее ионами Хе ${ }^{+}$. Молекулярнодинамическое моделирование структуры аморфного $\mathrm{SiO}_{2}$, обогащенного кислородными вакансиями, показало возможность возникновения зародышей нанокластеров кремния, которые способны играть существенную роль в формировании и эволюции проводящих ток путей (филаментов) и тем самым влиять на параметры мемристора.
\end{abstract}

Ключевые слова: мемристивные структуры, диоксид кремния, филамент, ионное облучение, нанокластеры, молекулярно-динамическое моделирование.

DOI: 10.21883/PJTF.2020.01.48859.18003

В последние годы ведутся интенсивные исследования в области физики и техники нового класса приборов мемристоров [1]. Интерес к этим приборам обусловлен тем, что их применение позволит произвести революцию в целом ряде важнейших областей техники: от компьютеров до нейробиологических систем. Усилия исследователей сосредоточены на разработке пригодных для практического применения мемристивных устройств с использованием пленок неорганических соединений, таких как оксиды кремния, титана, тантала, гафния, циркония; проводятся также исследования других, в том числе органических, соединений [2]. Наиболее совместимыми с технологией интегральных схем являются мемристоры на основе аморфного диоксида кремния $[3,4]$.

В настоящее время одним из основных недостатков мемристоров - структур, действие которых базируется на переходах из состояния с низким сопротивлением (CHC) в состояние с высоким сопротивлением (CBC) и обратно, - является плохая воспроизводимость параметров переключения при многократном (циклическом) воздействии напряжения. Наиболее вероятной причиной этого служит стохастический характер механизмов образования проводящих ток путей (филаментов) при первичной подаче напряжения (электроформовке) и последующих переключениях. Филаменты обычно зарождаются на концентраторах электрического поля, связанных с такими особенностями, как шероховатость границы раздела электрод-диэлектрик, флуктуации структуры и химического состава диэлектрика, что трудно контролировать при изготовлении мемристивных структур.

Основными атомарными агентами, участвующими в образовании и дальнейшей эволюции филаментов в мемристорах на основе аморфного оксида кремния, являются кислородные вакансии. Резонно предположить, что управляемое создание таких вакансий в приповерхностной области диэлектрика (в качестве возможных концентраторов электрического поля) уменьшит неконтролируемое влияние причин низкой воспроизводимости. В принципе это можно реализовать с помощью ионной имплантации. При ионном облучении $\mathrm{SiO}_{2}$ образуются так называемые каскады атомных смещений (что равносильно созданию высокой концентрации вакансий, в том числе кислородных). Можно предположить [5], что они будут играть роль зародышей филаментов, если обеспечить их пространственное разделение. Это требует выбора вида, энергии иона и дозы облучения. $\mathrm{B}$ настоящей работе экспериментально исследовано изменение параметров мемристора на основе $\mathrm{SiO}_{2}$ под действием облучения ионами $\mathrm{Xe}^{+}$.

Высокая концентрация кислородных вакансий в области филамента $[1,3,4]$ может существенно изменить локальную структуру $\mathrm{SiO}_{2}$ и повлиять на механизм переключения. Молекулярно-динамическое моделирование позволяет оценить характер такой структурной перестройки. В работе приведены результаты соответствующего расчета.

Для создания мемристивной структуры на подложке $\mathrm{TiN} / \mathrm{SiO}_{2} / \mathrm{Si}$ магнетронным распылением поверх $\mathrm{TiN}$ наносилась пленка $\mathrm{SiO}_{2}$ толщиной $40 \mathrm{~nm}$. Облучение проводилось ионами $\mathrm{Xe}^{+}$с энергией $5 \mathrm{keV}$, для которых средняя глубина максимума концентрации вакансий, согласно SRIM (the stopping and range of ions in matter) [6], равна $17 \AA$. Выбор тяжелых ионов $\left(\mathrm{Xe}^{+}\right)$обусловлен стремлением к повышению концентрации вакансий в области каскада. После облучения методом магнетронного распыления через маску наносилось золото для создания верхних электродов площадью $\sim 10^{-2} \mathrm{~cm}^{2}$. Нижним электродом служил слой TiN. 

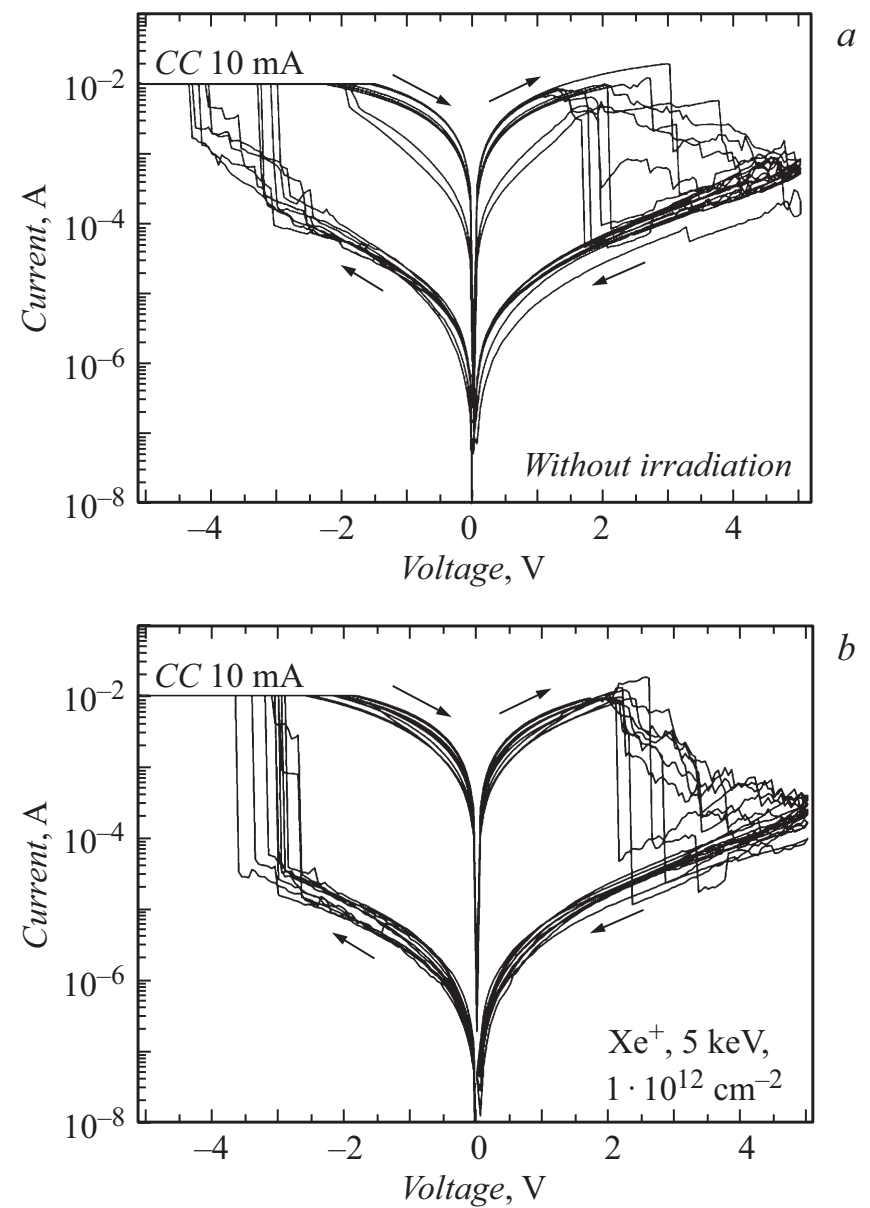

Рис. 1. Типичные BAX мемристивных устройств на основе $\mathrm{SiO}_{2}$ без облучения $(a)$ и при облучении ионами $\mathrm{Xe}^{+}$с дозой $1 \cdot 10^{12} \mathrm{~cm}^{-2}(b)$.

Оценка дозы облучения, обеспечивающей пространственное (в среднем) разделение каскадов с использованием SRIM, проводилась следующим образом. Определялись координаты изоконцентрационной поверхности для усредненного (по $2 \cdot 10^{5}$ ионов) каскада атомных смещений, на которой концентрация вакансий кислорода $\left(N_{v}\right)$ в 100 раз меньше ее максимальной величины $\left(N_{v \max }\right)$. Результаты обрабатывались с помощью специально созданной программы. Для выбранной энергии ионов $\mathrm{Xe}^{+}(5 \mathrm{keV})$ расчет дал значение среднего расстояния от точки падения иона $r=1.7 \cdot 10^{-7} \mathrm{~cm}$ для глубины, отвечающей выполнению соотношения $N_{v \max } / N_{v}=100$. Найденное значение $r$ позволяет оценить верхнюю границу дозы $\left(\Phi_{\max }\right)$, при которой каскады смещения еще можно считать неперекрывающимися. Соответствующая доза $\Phi_{\max } \approx 1 /(2 r)^{2}=9 \cdot 10^{12} \mathrm{~cm}^{-2}$.

Экспериментально исследованы результаты облучения для доз в интервале $10^{11}-10^{14} \mathrm{~cm}^{-2}$. На установке Agilent B1500A измерялись вольт-амперные характеристики (BAX) мемристивных структур. Для исключения пробоя применялось ограничение по току $(10 \mathrm{~mA})$ в CHC.
Наиболее заметное положительное влияние ионного облучения было отмечено для дозы $10^{12} \mathrm{~cm}^{-2}$. На рис. 1 представлены типичные BAX контрольных (не подвергнутых облучению) мемристивных структур и структур, модифицированных облучением с указанной дозой. Из рис. 1 следует, что ионное облучение улучшает воспроизводимость ВАХ при циклическом воздействии напряжения. Кроме того, наблюдается заметное увеличение отношения значений сопротивлений в СВС и CHC, измеренных при $0.5 \mathrm{~V}$. Увеличение этого отношения является важным эффектом, поскольку снижается вероятность случайных сбоев при работе мемристоров в качестве устройств памяти.

Полученные результаты подтверждают влияние локального введения кислородных вакансий на этапе образования филамента (электроформовки), а также в процессах переключения, на что указывалось и в работе [3].

Было проведено молекулярно-динамическое моделирование структурной перестройки аморфного $\mathrm{SiO}_{2}$ при избыточном содержании кислородных вакансий $\left(\mathrm{SiO}_{x}\right.$, $x=1.2)$. Размер моделируемого объекта $\mathrm{SiO}_{2}$ составлял $60 \times 60 \times 60 \AA$ и суммарно охватывал 11616 узлов $\mathrm{Si}$ и О. Аморфная структура $\mathrm{SiO}_{2}$ была смоделирована из структуры кристобалита стандартным методом: нагрев выше температуры плавления и последующее быстрое охлаждение [7]. Затем в центральной области объекта, имеющей размер $14 \times 14 \times 14 \AA$, случайным образом убирались кислородные узлы в количестве, обеспечивающем стехиометрическую формулу $\mathrm{SiO}_{1.2}$ (в данном случае 24 узла). Размер области $14 \AA$ сопоставим с типичным радиусом филамента [1] и потому отражает реальную ситуацию. Далее моделируемый объект подвергался процедуре минимизации потенциальной энергии в режиме, обеспечивающем сохранение объема и заданной температуры (NVT-термостата), при температурах в интервале 300-900 K, поскольку, согласно имеющимся в литературе оценкам [5], температура в области филамента в процессе работы мемристора может достигать максимальных значений, лежащих в этом интервале. Межатомное взаимодействие описывалось потенциалом Терсоффа, модифицированным для $\mathrm{SiO}_{2}$ [8]. Временной шаг в процессе интегрирования уравнений движения был равен $10^{-4} \mathrm{ps}$, а полное время моделирования составляло $\sim 10 \mathrm{~ns}$, т. е. на пять порядков больше типичного периода тепловых колебаний. Расчет проводился на вычислительном кластере ННГУ им. Н.И. Лобачевского с использованием программного кода LAMMPS [9].

Для оценки характера структурных изменений, происходящих в области филамента с высоким содержанием кислородных вакансий при различных температурах, строились парциальные радиальные функции распределения (РФР) атомов кремния. Эти функции для тех же температур сравнивались с РФР, рассчитанными в отсутствие вакансий. Для устранения влияния колебательного движения атомов при расчете РФР использовались усредненные („статические“) координаты атомных 

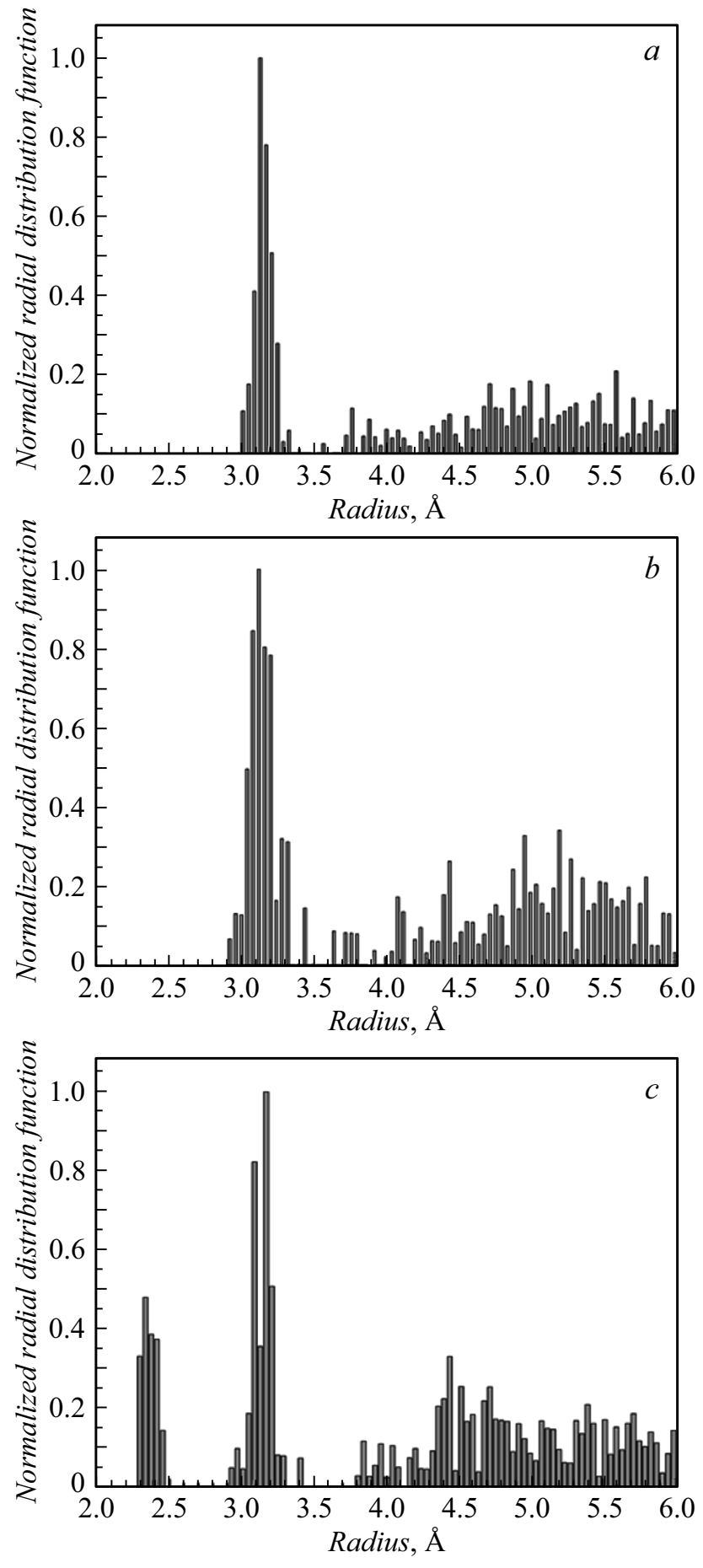

Рис. 2. РФР, нормированные на максимальные значения радиальной функции распределения узлов кремния, в моделируемой области размером $14 \times 14 \times 14 \AA$ без вакансий при температурах $300(a)$ и $900 \mathrm{~K}(b)$, а также с 24 вакансиями при температуре $900 \mathrm{~K}(c)$.

узлов, полученные для последних $10^{4}$ временны́х шагов расчета.

На рис. 2 в виде гистограмм приведены РФР, нормированные на максимальные значения этой функции, для модельного объема без вакансий при температурах 300 и $900 \mathrm{~K}$ и с вакансиями при температуре $900 \mathrm{~K}$. Отчетливо видно, что высокая концентрация вакансий привела к значительной перестройке взаимного расположения атомов. При этом после перестройки значение среднего межатомного расстояния для первой координационной сферы весьма близко к значению длины межатомной связи в кристаллическом кремнии $(2.34 \AA)$. Такую трансформацию структуры можно трактовать как начальный этап формирования кремниевых нанокластеров - так называемых прекурсоров. Результаты расчетов показали нарастание степени указанной трансформации с увеличением температуры. В отсутствие вакансий образования прекурсоров не наблюдается, но с ростом температуры имеет место ожидаемое уширение пика РФР.

Интервал времени ( 10 ns), за который произошло образование прекурсоров, дает основание считать, что обнаруженная в модельном эксперименте трансформация структуры имеет место и в реальных филаментах, тем более что времена, характерные для формовки и переключения, во много раз больше [10].

В ряде работ $[11,12]$ отмечена и экспериментально подтверждена важная роль нанокластеров кремния в процессах переключения в условиях отклонения их состава от стехиометрического (недостаток кислорода). Результаты расчета подтверждают возможность образования нанокластеров кремния в тонких пленках оксида кремния, используемых в мемристивных структурах.

Полученные результаты свидетельствуют также о возможности управления параметрами мемристоров на основе $\mathrm{SiO}_{2}$ методом ионной имплантации за счет контролируемого введения не только кислородных вакансий, но и избыточных атомов кремния.

\section{Финансирование работы}

Исследование выполнено при финансовой поддержке Российского фонда фундаментальных исследований в рамках научного проекта № 18-37-00456.

\section{Конфликт интересов}

Авторы заявляют, что у них нет конфликта интересов.

\section{Список литературы}

[1] Lee J.S., Lee S., Noh T.W. // Appl. Phys. Rev. 2015. V. 2. N 3. P. 031303 (1-57). DOI: 10.1063/1.4929512

[2] Ерохин В.B. Органические мемристорные приборы и нейроморфные системы. Автореф. докт. дис. М.: НИЦ „Курчатовский институт“, 2018. 42 с.

[3] Mehonic A., Shluger A.L., Gao D., Valov I., Miranda E., Ielmini D., Bricalli A., Ambrosi E., Li C., Yang J.J., Xia Q., Kenyon A.J. // Adv. Mater. 2018. V. 30. N 43. P. 1801187 (1-21). DOI: 10.1002/adma.201801187

[4] Gao D.Z., El-Sayed A.-M., Shluger A.L. // Nanotechnology. 2016. V. 27. N 50. P. 505207 (1-7). DOI: $10.1088 / 0957-4484 / 27 / 50 / 505207$ 
[5] Bersuker G., Gilmer D.C., Veksler D., Kirsch P., Vandelli L., Padovani A., Larcher L., McKenna K., Shluger A., Iglesias V., Porti M., Nafría M. // J. Appl. Phys. 2011. V. 110. N 12. P. 124518 (1-12). DOI: 10.1063/1.3671565

[6] Электронный ресурс. Режим доступа: http://www.srim.org/

[7] Cruz-Chu E.R., Aksimentiev A., Schulten K. // J. Phys. Chem. B. 2006. V. 110. N 43. P. 21497-21508. DOI: $10.1021 / \mathrm{jp} 0638960$

[8] Munetoha Sh., Motooka T., Moriguchi K., Shintani A. // Comp. Mater. Sci. 2007. V. 39. N 2. P. 334-339. DOI: 10.1016/j.commatsci.2006.06.010

[9] Электронный ресурс. Режим доступа: https://lammps.sandia.gov/

[10] Montesi L., Buckwell M., Zarudnyi K., Garnett L., Hudziak S., Mehonic A., Kenyon A.J. // IEEE Trans. Nanotechnol. 2016. V. 15. N 3. P. 428-434. DOI: $10.1109 /$ tnano.2016.2539925

[11] Manolov E., Paz-Delgadillo J., Dzhurkov V., Nedev N., Nesheva D., Curiel-Alvarez M., Valdez-Salas B. // J. Phys.: Conf. Ser. 2019. V. 1186. P. 012023 (1-6). DOI: $10.1088 / 1742-6596 / 1186 / 1 / 012023$

[12] Гисматулин А.А., Камаев Г.Н. // Письма в ЖТФ. 2016. T. 42. B. 11. C. $73-81$. 